Eliane Baader de Lima' ${ }^{1}$

\title{
O ornamento \\ no pensamento de John Ruskin
}

The Ornament in John Ruskin's thought

El adorno en el pensamiento de John Ruskin 


\title{
Resumo
}

O presente artigo pretende evidenciar e perceber a presença do ornamento vivo na formação do pensamento estético de John Ruskin. Suas reflexões sobre o trabalho expressivo na arquitetura, manifestado sobretudo em sua ornamentação, serão tomadas sob o conceito do fantástico paradoxo da imperfeição, que evidencia a vitalidade e o prazer do trabalhador em sua prática oficinal. Tal manifestação de vida e de felicidade somente poderia ser alcançada pela comunhão entre o trabalho manual e intelectual de seus artesãos..

Palavras-chave: John Ruskin; Arquitetura; Ornamento; Imperfeição.

\begin{abstract}
This paper aims to show and perceive the presence of the living ornament in the formation of John Ruskin's aesthetic thought. His reflections on the expressive work in architecture, manifested above all in its ornamentation, will be taken under the concept of the fantastic paradox of imperfection, which highlights the vitality and pleasure of the worker in his workshop practice. This manifestation of life and happiness could only be achieved by the communion between the manual and intellectual work of its artisans.
\end{abstract}

Keywords: John Ruskin; Architecture; Ornament; Imperfection.

\section{Resumen}

Este artículo pretende ressaltar y percibir la presencia del ornamento vivo en la formación del pensamiento estético de John Ruskin. Sus reflexiones sobre el expressivo trabajo en la arquitectura, manifestado especialmente en su ornamentación, serán tomadas bajo el concepto de la fantástica paradoja de la imperfección, que resalta la vitalidad y el placer del trabajador en su práctica de taller. Tal manifestación de vida y felicidad solo podría lograrse mediante la comunión entre el trabajo manual e intelectual de sus artesanos.

Palabras-claves: John Ruskin; Arquitectura; Adorno; Imperfección.

\footnotetext{
${ }^{1}$ Mestre em Arquitetura e Urbanismo pela Universidade Federal de Santa Catarina - UFSC, e graduada em Artes Visuais (licenciatura) pela Universidade Regional de Blumenau - FURB. Email: elianebaader@gmail.com 


\section{O Ornamento na arquitetura e o fantástico paradoxo}

As discussões que se formaram ao longo do oitocentos em relação às práticas artísticas e as novas formas do fazer industrial impulsionaram as transformações que se manifestariam, mais adiante, sobretudo na artes aplicadas. Os questionamentos acerca da natureza da arte e, principalmente, a sua relação com a sociedade industrial que se estabelecia e se firmava alimentaram as novas formas de se perceber a arte e a arquitetura. A maquinaria moderna proporcionou novos arranjos de produção fabril e facilitou a fabricação de objetos de uso cotidiano, anteriormente manufaturados nas oficinas de artífices e artesãos, alterando os modos de fazer até então estabelecidos. O sistema de corporações de ofício, que antes regulava a manufatura e as relações de trabalho, se extinguira e dava lugar, principalmente, à liberdade das relações econômicas. Em meio a tais discussões, o ornamento, concebido, desde a Antiguidade, como um elemento formador do caráter da beleza nas artes, sobretudo na arquitetura, parecia ter seu propósito abalado. A falta de qualidade artística dos objetos ornamentados produzidos pela indústria, assim como as inesperadas aplicações de padrões ornamentais dissociados de seus conjuntos originais, principalmente após a primeira Exposição Universal realizada em 1851, colocaram o ornamento no centro de um caloroso debate - incialmente entre aqueles que o reivindicaram, em meados do século XIX e, posteriormente, entre aqueles que o destituíram, no início do século XX. Dentre os primeiros, o inglês John Ruskin (1819-1900), um dos mais importantes pensadores do oitocentos, reclamava pela presença do ornamento vivo ${ }^{1}$ dos antigos artesãos góticos no fazer arquitetônico. Em seus estudos sobre a natureza da arquitetura Gótica, o autor dedicou-se a elencar os elementos que constituíam a "expressão mental" e a "expressão formal" de sua arquitetura. Ao finalizar a definição de "savageness", o primeiro destes elementos, Ruskin assinalava que deveríamos aceitar como uma "lei universal" que "nem a arquitetura nem qualquer outro nobre trabalho do homem poderiam ser verdadeiramente bons se não fossem imperfeitos". E, mais adiante, declarava que "a primeira causa da decadência das artes da Europa" teria sido "a insaciável exigência da perfeição" (RUSKIN, 1904, v.2, p. 204). A aparente contradição apresentada pelo autor e nomeada por ele como o "fantástico paradoxo" talvez seja uma das maiores contribuições do pensamento crítico ruskiniano. Ao reconhecer a imperfeição humana como formadora do caráter da beleza, Ruskin colocava outra forma de se compreendê-la, em contrapartida à doutrina mimética que regeu os preceitos nas práticas artísticas até o final do século XVIII. Embora considerasse a beleza em sua forma perfeita, Ruskin tornava mais complexo o seu entendimento ao reconhecer a imperfeição e as limitações humanas reinterpretadas como virtude.

Em suas reflexões sobre o trabalho artístico na arquitetura, Ruskin declarava que o ornamento vivo somente poderia ser alcançado pela comunhão entre o trabalho e o pensamento de cada trabalhador envolvido na edificação da obra. E, sobretudo, pelo prazer que se manifestaria no operário em consequência de tal comunhão.

1 A expressão ornamento vivo está intimamente vinculada ao conceito do fantástico paradoxo ruskiniano. Refere-se ao ornamento feito pelo artesão numa condição que Ihe permite conjugar trabalho e pensamento em sua prática oficinal. 
As influências da arquitetura na vida e felicidade do trabalhador que ajudou a edificá-la, assim como a indissociável ligação entre arte, vida e moralidade nas práticas artísticas, eram questões que haviam sido desprezadas e esquecidas, segundo Ruskin, na maioria dos escritos sobre arquitetura ${ }^{2}$. A arquitetura seria a expressão do temperamento moral tanto daqueles que entregaram o seu trabalho em sua edificação quanto daqueles para quem foi produzida. E uma de suas maiores qualidades seria poder acolher a mais simples manifestação mental de vida e felicidade do trabalhador na execução do seu ofício. A boa arquitetura seria aquela que confessasse a comunhão entre a mente inventiva e a mão executiva de seus trabalhadores em sua materialidade. E o fantástico paradoxo fundamenta-se nesta comunhão, uma vez que a imperfeição estaria intimamente ligada à felicidade executiva do trabalhador em sua prática oficinal. Se ao trabalhador fosse permitida uma certa liberdade de pensamento, incentivando sua imaginação e sua emoção, a felicidade o conduziria na execução do seu ofício. E a expressão animada dos trabalhadores que ajudaram a erguer a edificação deixaria, no corpo mesmo daquela matéria, os sinais e os indícios de tal presença humana, revelados, principalmente, em sua ornamentação.

Em As Sete Lâmpadas da Arquitetura, publicada em 1849 e, sobretudo, nos três volumes de As Pedras de Veneza, concebidos entre 1851 e 1853, Ruskin teceu suas principais considerações sobre o ornamento na arquitetura. Segundo o autor, as duas principais virtudes da arquitetura seriam "seu poder ou boa construção, e sua beleza ou boa decoração" (RUSKIN, 1903, v.1, p.65). A primeira representaria a parte inteligente do homem, manifestada na estrutura do edifício; a segunda, a parte afetuosa, demonstrada em sua decoração. A arquitetura deveria revelar o equilíbrio entre estas duas fontes de prazer, "utilidade e esplendor", e ambas deveriam ser admiradas pelo "grandioso poder e coração do homem na coisa" (RUSKIN, 1903, v.1, p. 66). Entretanto, para que a decoração fosse realmente bela, suas afeições precisariam ser vívidas, honestamente mostradas e inscritas nas coisas justas e corretas.

Considerando o menor e o maior nível de comunhão entre a mão executiva e a mente inventiva do trabalhador, Ruskin dividia o sistema de ornamento em três ordens: o ornamento servil, executado por um artesão numa condição de absoluta servidão; o ornamento constitucional ou medieval, o único verdadeiramente cristão porque reconhecia o "valor individual de cada alma" e permitia a contribuição de cada trabalhador, aceitando, porém, suas incapacidades; e o ornamento revolucionário ou renascentista que, por não admitir a inferioridade executiva de seus ornamentos, intentava somente adestrar o artesão no desejo de alcançar a perfeição. Estas três ordens estão estreitamente ligadas tanto ao nível de imperfeição executiva permitido ao artesão quanto à presença viva do trabalhador na fatura do ornamento. E a imperfeição executiva estaria vinculada, em maior ou menor grau, a uma das condições da arte que, segundo o autor, seria essencialmente arquitetônica - a abstração ${ }^{3}$. A abs-

2 Cf. CooK in: RUSKIN (1903, introdução). E. T. Cook e Alexander Wedderburn são os editores da compilação Works, que reúne em 39 volumes as publicações de John Ruskin, disponibilizada pela Lancaster University / Ruskin Library. Uma parte desta compilação foi utilizada para fundamentar a dissertação de mestrado - O fantástico paradoxo no pensamento estético de John Ruskin e a presença do artífice na arquitetura rural de Santa Catarina - da qual este texto resulta. 0 recorte utilizado refere-se às obras ruskinianas publicadas sobre arquitetura e parte dos textos sobre economia política da arte, quando Ruskin intensifica sua crítica social e evidencia a importância dos fundamentos sociais da arte. Além das publicações do autor, as considerações de alguns comentadores a respeito de sua obra, entre eles, Clark, Landow e Townsend, juntamente com Cook e Wedderburn, contribuíram para as reflexões tecidas ao longo do texto.

3 Outra condição da arte, essencialmente arquitetônica, seria a proporção. Para que a proporção fosse alcançada na arquitetura, uma parte da composição do 
tração no ornamento arquitetônico consistiria em recolher o essencial da coisa a ser representada e, neste sentido, para Ruskin, toda arte seria abstrata em sua intenção primeira. Mas entre a colheita da essência da forma e a sua efetiva representação, o ornamento nasceria de linhas simples, porém substanciais, podendo chegar à perfeita execução formal. Entretanto, o arquiteto moderno não poderia, de acordo com o autor, considerar somente o trabalho de mãos hábeis para produzir formas perfeitas de ornamento em sua obra arquitetônica. Ele deveria conceber seu projeto considerando a colaboração de trabalhadores comuns, tomando os elementos essenciais daquilo que deveria ser representado, de forma que o homem mais ignorante e a mão mais fraca pudessem executá-los. "Esta é a definição da mais pura abstração arquitetônica. Ela é formada pelos pensamentos profundos e laboriosos dos maiores homens, colocados em tais letras fáceis que podem ser escritas pelos mais simples" (RUSKIN, 1903, v.1, p. 290). Contudo, a atividade executiva na arquitetura deveria revelar a unidade entre as mãos e o pensamento dos vários homens que ajudaram na construção do edifício. E deveria permitir, também, um certo grau de liberdade para que os trabalhadores pudessem participar da elaboração da obra, entregando tanto suas habilidades quanto confessando suas incapacidades.

A abstração, no pensamento ruskiniano, também está relacionada à hierarquia compositiva que constitui toda arte decorativa. Para o autor, a verdadeira natureza da arte decorativa estaria na sua condição de ser realizada para um determinado lugar e, neste lugar, estabelecer uma posição de comando ou de subordinação em relação aos demais objetos artísticos. E, segundo Ruskin, não existiria arte de "primeira categoria" que não fosse decorativa, uma vez que toda arte até então produzida teria sido feita para ocupar um lugar definido. Nesta conjuntura, o autor distinguia duas ordens de arte decorativa, uma natural e outra convencional ${ }^{4}$. A primeira deveria ser destinada a ser vista e realizada com perfeição. Fazem parte desta ordem as pinturas e esculturas realizadas pelos "grandes mestres" e estas não poderiam ser consideradas um ornamento arquitetônico, "exceto neste sentido vago em que qualquer coisa bonita é dita para ornamentar o lugar em que se encontra" (RUSKIN, 1903, v.1, p. 284). Tais objetos artísticos assumiriam uma posição de comando na hierarquia compositiva da arte decorativa e, neste caso, a arquitetura estaria subordinada à escultura e à pintura. Já a segunda ordem de arte decorativa diz respeito às formas do ornamento propriamente dito e Ruskin declarava que tais formas deveriam estar relacionadas com a beleza conveniente em relação ao lugar, ao material e à serventia do ornamento. O convencionalismo em consequência do lugar destacava, primeiramente, que uma expressão de beleza deveria ser apresentada no momento em que o poder mental dos homens não estivesse ocupado com alguma outra coisa, pois o repouso seria condição peculiar de sua apreciação. Uma beleza encantadora apresentada para um "olho cansado" e uma mente ocupada não seria um elemento de prazer, assim como

edifício deveria ser principal em relação às demais. Para Ruskin, não haveria proporção numa composição entre "coisas iguais". Entre "coisas iguais" poderia haver somente simetria e, compor, seria "organizar coisas desiguais". A regra principal da proporção, então, seria: "tenha uma coisa acima do resto, seja tamanho, função ou interesse". Cf. Ruskin (1903, p. 164).

4 Rafael Cardoso, tradutor dos textos de A Economia Política da Arte, de Ruskin, salienta que esta distinção entre arte natural e arte convencional seria fundamental no pensamento ruskiniano. Por "natural", o autor entendia "toda forma de representação artística que vis[asse] reproduzir a aparência do mundo visível". Por "convencional", o autor entendia "toda forma de representação artística' que fizesse uso de "elementos abstratos" correspondentes a uma "redução convencionada". Cf. Ruskin (2004, p. 159), N. do T. 
tornaria a sua frequência sem sentido e a sua forma vulgarizada. Outro ponto que deveria ser notado no convencionalismo em consequência do lugar refere-se à distância em relação aquele que observa e aprecia o ornamento criado. Considerando o maior ou menor grau de rusticidade no tratamento da forma, quanto mais próximo do chão, maior o grau de perfeição e, quanto mais distante do chão, menor o grau de perfeição formal. O convencionalismo em virtude das limitações do material assinalava que a beleza aparente da obra artística deveria ser diminuída ao invés de ser representada desonestamente. A verdade e a honestidade executiva deveriam ser a intenção primeira do ornamento. Se a natureza do material empregado em sua fatura não lhe permitisse a perfeita execução formal, a beleza deveria ser reduzida aos limites de tal material. E, por último, o convencionalismo em relação à serventia ressaltava o nível de subordinação de um ornamento numa composição. Um ornamento de ordem inferior não poderia concorrer com um ornamento de ordem superior, e sua subordinação deveria ficar evidente restringindo, em maior ou menor grau, o uso das formas naturais.

Na hierarquia compositiva da arte decorativa é importante ressaltar que a principal característica que constitui a natureza do ornamento, no pensamento ruskiniano, seria, então, a sua condição de subordinação. Todo ornamento deveria estar subordinado tanto às partes quanto a um conjunto maior ao qual pertence, e sua especial condição de beleza residiria em ser "bonito em seu lugar e em nenhum outro". Assim, o ornamento arquitetônico deveria alcançar sua unidade na totalidade do edifício, no qual nenhum elemento poderia ser acrescentado ou retirado sem comprometer sua beleza. Se algum elemento pudesse ser removido sem corromper a unidade do conjunto, não seria ornamento, mas "deformidade e oneração". Em contrapartida, a escultura ou a pintura, quando realizadas de maneira "natural" e com perfeição formal não confessariam subordinação ao conjunto e alcançariam a completude em si mesma. Seriam objetos artísticos de "vontade independente", próprios do mestre e de sua produção ${ }^{5}$. $O$ "ornamento, o servo, é muitas vezes formal, onde a escultura, o mestre, teria sido livre; o servo é muitas vezes silencioso onde o mestre teria sido eloquente; ou apressado, onde o mestre teria sido sereno" (RUSKIN, 1903, v.1, p. 285).

Cabe ainda ressaltar que a beleza do ornamento, para Ruskin, deveria estar fundamentada na lei das formas naturais e haveria, também, uma hierarquia ali presente. Quanto mais próximo das formas naturais e orgânicas, maior a sua superioridade; quanto mais próximo das linhas abstratas, dos "contornos mais frequentes dos objetos naturais", maior a inferioridade do ornamento. Entretanto, considerando a honestidade executiva, deveríamos preferir aquilo que fosse melhor, mesmo que de uma ordem inferior, do que aquilo que fosse pior de uma ordem superior. Neste sentido, a frequência da beleza também deveria ser observada. As formas mais belas e supe-

\footnotetext{
5 Apesar de fazer uma distinção entre a arte e as habilidades dos "grandes mestres" e as demais manifestações artísticas praticadas por homens comuns, para Ruskin, o artista e o artesão, no exercício de sua artesania, deveriam ser, antes de tudo, trabalhadores. Tal distinção parece figurar como uma forma de distinguir a natureza da arte praticada por cada um, não se referindo a uma divisão de caráter elitista. A arte, em suas diversas naturezas, estaria ligada, ao mesmo tempo, ao dom natural e ao exercício oficinal.

6 A hierarquia compositiva da arte decorativa parece, também, ser regida pelo princípio da ajuda mútua, no qual cada uma das partes colaboraria para a beleza do conjunto maior. Haveria, portanto, uma interdependência entre os elementos, manifestada na composição do corpo arquitetônico, que revelaria o relacionamento das partes com o todo. Para Claudio Amaral, o pensamento ruskiniano seria orientado pela "política da ajuda mútua" existente na Natureza. Assim, a composição arquitetônica deveria ser conduzida pela mesma lógica existente nas formas naturais e promovida pela política da ajuda mútua. Cf. Amaral (2019, $\left.\mathrm{n}^{\circ} 235\right)$.
} 
riores do ornamento deveriam ser preservadas enquanto as formas de beleza inferior, espalhadas, uma vez que a "Natureza poupa a sua beleza mais alta e esbanja a sua beleza inferior"7. O ornamento arquitetônico seria, então, a "parte principal da arquitetura", a "parte feliz" 8 de uma edificação, em que o homem encontraria primeiro as formas mais encantadoras, depois recolheria destas formas naturais aquilo que fosse mais apropriado para a expressão do objeto a ser representado e, por último, elegeria o lugar adequado e conveniente para que tal objeto pudesse ser apreciado, colaborando com o arranjo compositivo maior. O ornamento seria uma partilha, uma comunhão das formas naturais na vida do homem - a mais pura "expressão de alegria do homem na obra de Deus" (RUSKIN, 1903, v.1, p. 264).

\section{A fantasia grotesca e a rudeza de expressão}

O sistema medieval de ornamento manifestado, sobretudo, na natureza da arquitetura Gótica, seria o único, segundo Ruskin, que permitiu a unidade entre o trabalho manual e intelectual de seus artesãos, favorecendo a execução de um ornamento vivo. E um dos principais elementos de poder de sua arquitetura teria sido a aceitação da "energia inculta e rude do trabalhador". Permitir ao operário uma certa liberdade de pensamento no exercício do seu ofício e acolher as mais simples manifestações expressivas do seu trabalho mental foram, para Ruskin, o aspecto mais admirável da arquitetura Gótica. "E é isso que devemos fazer com todos os nossos operários: procurar a sua parte pensante e fazê-la despertar não importando o que perderemos com isso, nem com que falhas e erros sejamos obrigados a assumir" (RUSKIN, 1904, v.2, p. 191). Tal liberdade de pensamento alimentada, principalmente, pela "saudável alegria da fantasia", permitiria ao homem comum tanto manifestar sua "rudeza de expressão" quanto entregar-se a uma "fantasia grotesca".

O "grotesqueness", outro importante elemento que caracteriza a natureza da arquitetura Gótica, era, para o autor, uma admirável condição de "fantástica imaginação"' que também deveria estar presente na prática oficinal do trabalhador. Considerando o maior ou o menor grau de fantasia no homem e na materialidade por ele construída, Ruskin sugeria a humanidade dividida em quatro classes, cada classe correspondendo a um tipo de expressão: aqueles que brincam com sabedoria, aqueles que brincam por necessidade, aqueles que brincam desordenadamente e aqueles que não brincam. A primeira classe refere-se aos homens que cultivam uma nobre condição mental de trabalho intelectual, e este estado mental seria inatingivel para

\footnotetext{
7 Na Lâmpada da Beleza, um dos sete espíritos ou lâmpadas da arquitetura, Ruskin faz uma comparação entre as flores e folhas de uma roseira. Ao explicar sobre a frequência da beleza, embora onde houvesse uma rosa houvesse também folhas, cada um em sua quantidade adequada, não haveria "muitas rosas no arbusto como existem folhas". Cf. Ruskin (1903, p. 143).

8 Para Ruskin, "a ornamentação é a parte principal da arquitetura. Ou seja, a mais alta nobreza de um edifício não consiste em ser bem construído, mas em ser nobremente esculpido ou pintado". Cf. Ruskin (1904, p. 83).

9 Numa palestra sobre A Influência da Imaginação na Arquitetura apresentada aos membros do Architectural Association, em 1857, Ruskin afirmava que a os dons que fariam do homem um artista seriam, sobretudo, aqueles da "simpatia e da imaginação". Para Ruskin o arquiteto deveria ir além dos poderes de manipulação, cálculo e observação; ele deveria "nos contar uma fábula". E ele deveria, também, ir além das regras da proporção arquitetônica se quisesse que sua arquitetura pudesse ensinar, melhorar ou alegrar alguém. "(...) vocês mergulharão num estado em que não podem nem mostrar, nem sentir, nem ver nada, senão que um está para dois como três está para seis. E neste estado como deveríamos ser chamados? Homens? Eu acho que não. 0 nome correto para nós seria - numeradores e denominadores. Frações vulgares". Cf. Ruskin (1905, p. 354).
} 
a maioria da humanidade. A segunda classe corresponde à maior parte dos homens que, pelas condições de vida, entregam a sua energia a trabalhos cansativos nos quais as suas faculdades mais nobres, como a fantasia, não são requeridas. No final do dia de trabalho, estes homens estão ávidos por alimentar sua imaginação, sua curiosidade, sua fantasia; "estão todos famintos pela comida que o trabalho do dia os negou" (RUSKIN, 1904, v.3, p. 154). E eles colocam-se ao exercício da fantasia o mais breve que podem para se ressarcirem deste alimento. A terceira classe diz respeito aos homens que se entregam à diversão desordenadamente, seja pelas circunstâncias, seja pela falta de princípios. A última classe refere-se àqueles homens que restringem qualquer forma de fantasia. Para Ruskin, o mais perfeito estado da sociedade, equilibrado em suas relações de trabalho, seria aquele formado pelas duas primeiras classes: entre aqueles que brincam com sabedoria ou por necessidade, entre pensadores e trabalhadores. Ainda segundo o autor, para cada trabalhador que possui o mais fino instinto sobre a perfeição de linhas e a harmonia de cores, vinte possuem um "humor árido" e uma fantasia rude. Isso não quer dizer que as faculdades do segundo tipo tivessem sido dadas aos homens em maior número do que as do fino senso de beleza, mas que estas seriam mais fortemente exercidas em nossas relações diárias e desenvolvidas pelos interesses que tomamos nos assuntos da vida comum, enquanto que as primeiras não. Por isso, ao trabalhador, deveria ser permitido entregar-se à expressão de uma forma viva e animada, embora rude, do que entorpecer-se na busca por uma beleza perfeita.

Dentre os elementos ${ }^{10}$ que constituem a natureza da arquitetura Gótica, savageness e grotesqueness parecem melhor definir o ornamento vivo reverenciado por Ruskin nas práticas artísticas de seus antigos artesãos. Ambos seriam a manifestação do mais vivo poder mental de seus trabalhadores revelados na materialidade de sua arquitetura, evidenciando a inseparável ligação entre as formas externas e a energia que animava os artesãos góticos em suas práticas artísticas. Ambos representariam a conjugação do pensamento que inventa e se conforma da mesma maneira que orienta as mãos que executam. E ambos testemunhariam a aceitação da imperfeição e das incapacidades humanas também como constituintes do caráter da beleza.

Se o sistema medieval de ornamento considerava o valor individual de calma alma, teria sido no Renascimento, segundo Ruskin, o que as práticas artísticas começaram a dar os primeiros passos de sua corrupção. Para o autor, a habilidade dos "grandes mestres" da escola renascentista nos revelou uma perfeição de execução e uma "profundidade de saber" que acabou por lançar "na sombra toda a arte precedente". A partir de então, a perfeição passou a ser requerida em todo o fazer artístico. Exigir a perfeição na pintura e na escultura não fora tão prejudicial, de acordo com o autor, porque a fatura do objeto artístico é feita, normalmente, por um artista. Mas a arquitetura, enquanto arte de natureza partilhada, precisa da colaboração de homens comuns para sua edificação e exigir a perfeição executiva de simples operários teria sido um dos seus maiores erros. Tal exigência acabou desprezando e extinguindo, na prática oficinal de seus trabalhadores, todo o poder de pensamento e de fantasia que

10 São seis os elementos relacionados por Ruskin que constituem a natureza da arquitetura Gótica: Savageness, Changefulness, Naturalism, Grotesqueness, Rigidity e Redundance. 
somente poderiam ser expressados rudemente. E, no esforço de conferir aos trabalhadores comuns a aptidão e a capacidade executiva dos "grandes mestres", o poder original do verdadeiro ornamento se corrompia e a edificação inteira tornava-se a expressão de uma "imbecilidade bem-educada" - já que a perfeição executiva, para o autor, não poderia ser alcançada por um operário sem o sacrifício do seu corpo, da sua alma e do seu pensamento.

Um dos principais elementos que caracteriza a natureza da escola renascentista e o seu temperamento moral teria sido, segundo Ruskin, o "orgulho da ciência". Ao julgar a arte e a ciência como "uma só e mesma coisa" e ao requerer a ciência para alcançar a perfeição nas práticas artísticas, considerando-a como o primeiro elemento a ser expresso na obra, a escola renascentista intentava produzir artistas. O dom natural, a "emoção verdadeira" e a "simplicidade de expressão", que antes animavam as práticas artísticas, agora estavam subjugados à polidez acadêmica.

\begin{abstract}
Mais de um pedreiro de aldeia representaria com uma fantasia grosseira, mas original, temas bíblicos ou outros, mas somos arrogantes demais para deixá-lo fazer ou para aceitar sua obra executada, e o pobre sujeito continua polindo os cantos das suas pedras, enquanto nós construímos nossas igrejas com pedras quadradas, lisas, e acreditamos ser sábios. (RUSKIN, 1992, p. 74).
\end{abstract}

O método e a ciência impostos à arte provocaram perdas profundas no vigor artístico, segundo Ruskin, impossíveis de se avaliar. A percepção e o sentimento que deveriam impulsionar as práticas artísticas foram submetidos ao conhecimento científico e ao raciocínio. A fé, que antes animava a emoção primeira e a expressão sincera na obra de um pintor religioso, não estava mais presente na obra do "grande pintor" culto, porém, incrédulo. Quando os conhecimentos da ciência passaram a ser considerados como a essência da arte e não mais como seu apoio, quando a técnica começou a colocar-se sobre a emoção e a natureza da alma humana, a prática artística, de acordo com Ruskin, começou a perder a sua energia vital. Na medida em que a ciência tomava corpo na arte, a vida, as emoções e os sentimentos acabaram sendo expulsos de sua prática. Para o autor, a ciência poderia ser um dos alimentos do espírito, mas não o único. $\mathrm{E}$, se consumida sem excessos, ela poderia ser um "alimento sadio", não extinguindo os poderes de imaginação e emoção que deveriam conduzir o fazer artístico.

A perfeição executiva exigida pela escola renascentista teria levado à degradação das duas principais características do verdadeiro ornamento: a subordinação à completude do arranjo compositivo e a necessária presença viva dos artesãos em sua fatura. Quando o trabalhador comum foi treinado a exibir as habilidades e os conhecimentos próprios dos "grandes mestres", as porções menores, assim executadas, deixaram de conformar-se e cada detalhe tornou-se principal. Cada porção desvirtuou-se do conjunto maior ao qual deveria estar subordinada, levando à exuberância do ornamento. A exuberância do ornamento, segundo Ruskin, seria uma forma de degradação presente em quase todas as escolas de arte ${ }^{11}$. E uma de suas

11 No terceiro volume de As Pedras de Veneza, Ruskin classifica a arquitetura da Renascença em três fases: Primeira Renascença, que introduziu os elementos de corrupção na escola gótica; Renascença Romana, que corresponderia à perfeição do estilo; e a Renascença Grotesca, que seria a corrupção da própria Renascença. Para o autor, a Primeira Renascença corresponderia à corrupção e à extravagância do próprio Gótico: "(...) sem a luxúria e a perda de vigor que 
principais causas seria a falta de Temperança nas práticas artísticas. Esta virtude que modera as ações humanas era, para o autor, a "salvaguarda da maior beleza em toda a obra visível", e significava "o poder que governa a mais intensa energia e impede a sua atuação de qualquer maneira, senão como deveria" (RUSKIN, 1904, v.3, p. 6). Ao regular os hábitos morais dos homens, a Temperança regularia, também, as suas formas de expressão. A exigência da perfeição revelada na exuberância do ornamento demonstraria, igualmente, a perda do vigor nas práticas artísticas, já que ao artesão não era mais permitido a unidade entre trabalho e pensamento. E exigir a perfeição executiva sem permitir qualquer liberdade de pensamento seria, para o autor, um trabalho servil, não um trabalho livre. Embora a perfeição formal fosse alcançada e a exuberância do ornamento pudesse nos emocionar pela aparência de suas formas, a arte, assim praticada, seria nula em vigor e invenção, uma vez que a presença viva do trabalhador, sua alma e seu pensamento, já teriam se perdido por inteiro.
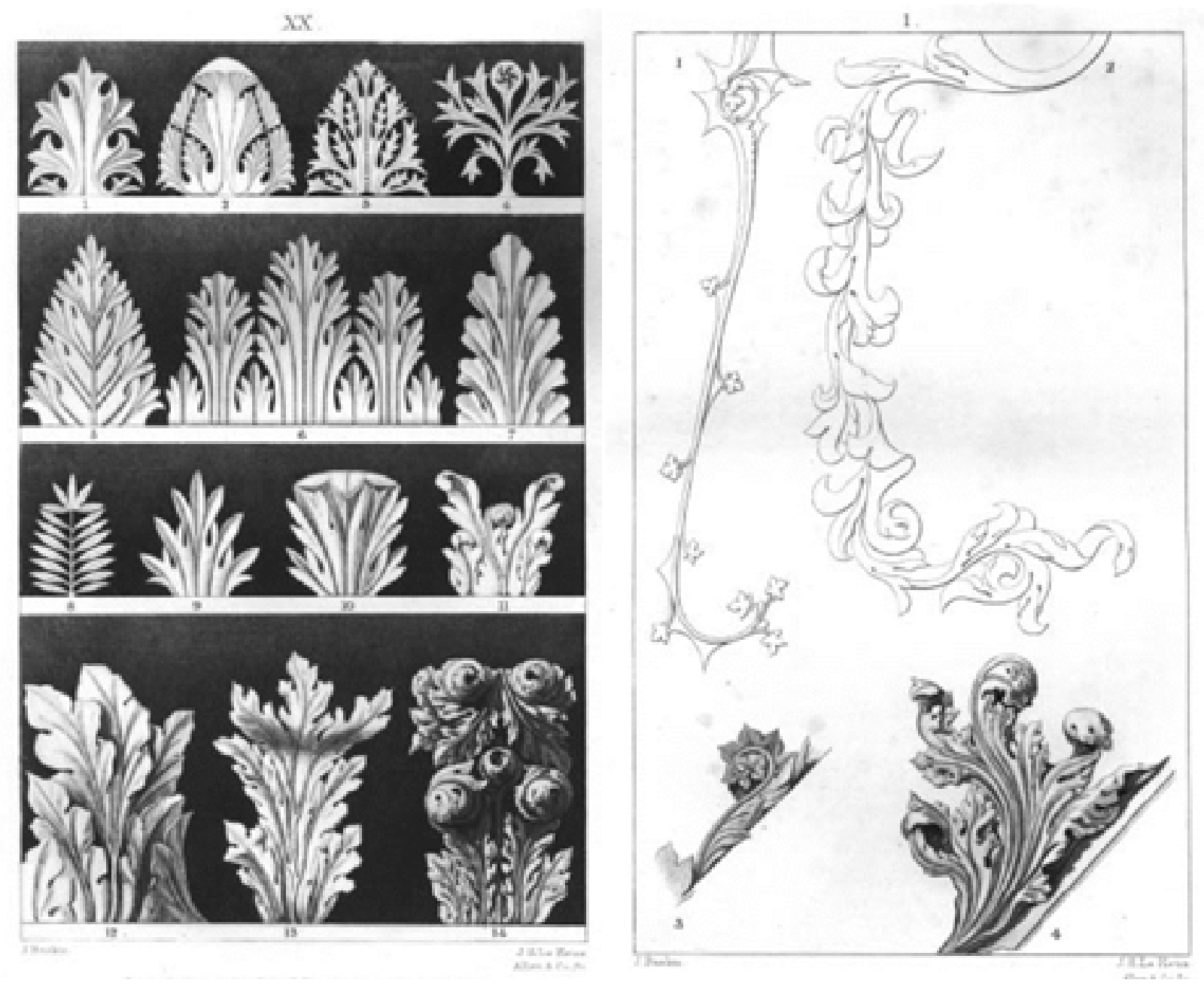

Fig. 1 e 2 - desenhos de Ruskin. Fonte: RUSKIN, 1904, v. 2, p.431 e v.3, p.9.

A exuberância do ornamento proveniente da intemperança nas práticas artísticas pode ser melhor observada na análise feita por Ruskin em relação ao desenho das folhagens de alguns capitéis venezianos. Na Figura 1, os primeiros doze desenhos 
representariam uma transição saudável da expressão bizantina até a mais bela expressão gótica, enquanto que os dois últimos desenhos caracterizariam o declínio e a corrupção do próprio gótico. Segundo o autor, embora a expressão de vida seja diferente nos desenhos bizantinos e góticos, ambos expressariam, igualmente, a Temperança em suas curvas, o que permitiria, ao olho, o descanso necessário para sua apreciação. Já os dois últimos desenhos, que representam o desvirtuamento do gótico, seriam o sinal "não de uma mente que amava a complexidade, mas de uma mente que não sabia saborear a simplicidade" e que, exausta e sem vida, entregava-se aos detalhes e ao prazer desmedido (RUSKIN, 1904, v. 3, p. 10). Na figura 2, Ruskin tece a mesma análise em relação à Temperança na curvatura do desenho do ornamento, observando a ornamentação de um manuscrito normando-francês do século XIII e um ornamento italiano do século XV.

Entretanto, é importante ressaltar que a crítica ruskiniana à escola renascentista não se referia aos grandes artistas que conseguiram expressar a mais vigorosa natureza humana, oferecendo trabalho e pensamento na fatura de suas obras. "A força desses grandes homens era bastante poderosa para que eles pudessem unir a ciência à invenção, o método à emoção, o apuro ao fogo da inspiração" (RUSKIN, 1992, p. 113). Os preceitos que regulam tal escola são criticados, pelo autor, não pela disposição que regem mas quando as certezas teóricas que postulam se sobrepõem a natureza da alma humana daquele que faz o objeto artístico, seja ele um artista ou um artífice. Da mesma maneira, perfeição e imperfeição não estão confrontadas em seu pensamento. Ambas deveriam revelar a manifestação de vida no trabalho expressivo do homem. Se a perfeição executiva fosse alcançada naturalmente, mantendo-se a completude de vida e pensamento na coisa produzida, a beleza estaria ali presente. Mas se para alcançá-la toda a imperfeição, que caracteriza a rudeza de expressão do homem comum, tivesse de ser eliminada, restando apenas um homem sem vida que produz uma obra também inanimada, o verdadeiro espírito da beleza teria se corrompido inteiramente.

A crítica que Ruskin tecia em relação à escola renascentista, por desconsiderar a presença viva do trabalhador em sua prática oficinal, se estendia, igualmente, à sociedade inglesa do século XIX. A produção fabril e a "grande invenção civilizada da divisão do trabalho" desconsiderava, da mesma maneira, a presença viva do operário. Ao comparar o trabalhador inglês e o trabalhador veneziano na fabricação do vidro, Ruskin assinalava as diferenças fundamentais que conduziam o ofício e a materialidade produzida por cada um. O "moderno vidro" inglês era claro e exato em sua aparência, e o operário que o produzia colocava toda a sua energia ao arredondar as curvas e afiar as bordas para alcançar a forma perfeita. Já o "velho vidro" veneziano era turvo e irregular em sua aparência, e o operário que o fabricava não colocava a sua energia para afiar as bordas, mas inventava um novo desenho em cada peça que produzia. Enquanto o primeiro havia se tornado uma maquinaria humana ou uma "ferramenta animada" a serviço da moderna manufatura inglesa, o segundo era tomado pela invenção e pelo pensamento em seu trabalho. Para Ruskin, o trabalho expressivo poderia transformar o homem numa ferramenta precisa ou poderia transformá-lo numa criatura pensante. Ao transformá-lo numa ferramenta, todos os 
seus poderes de emoção e de pensamento seriam reduzidos à precisão maquinal enquanto que, transformando-o numa criatura pensante, toda a sua capacidade mental e imaginativa se manifestaria em sua rudeza de expressão. Mas para que isso fosse realmente possível era preciso aceitar as imperfeições do gesto vivo também como constituintes daquilo que se entende por beleza.

\section{Considerações finais}

O fantástico paradoxo da imperfeição postulado por Ruskin, ao reclamar pela presença viva do trabalhador e pela felicidade executiva em seu ofício, acabava por lançar profundos questionamentos acerca da moralidade ou da imoralidade do sistema produtivo vigente - sobretudo o quanto o processo fabril e capitalista poderia colaborar para o desvirtuamento da condição humana, deturpando a sensibilidade, a moralidade e a ética ${ }^{12}$. Para o autor, a fortuna e a riqueza de uma nação não deveria estar ligada à quantidade de mercadoria fabricada ou de lucro produzido, mas deveria estar intimamente vinculada à quantidade de vida produzida por meio do seu trabalho. Suas reflexões sobre as práticas artísticas, sobretudo acerca do trabalho na arquitetura se estenderam para as relações sociais, quando o autor se dedicou aos textos sobre a economia política da arte. No pensamento crítico ruskiniano, há um inquestionável vínculo entre ética e estética. Da mesma forma que em seus textos sobre arquitetura, as considerações estéticas são alimentadas por observações de caráter ético-moral, em seus textos sobre a economia política da arte, as considerações éticas sobre o trabalho e as relações sociais são sustentadas por observações de cunho estético. Esta seria a base de sua crítica social e que revela a importância dos fundamentos sociais da arte em sua concepção de sociedade. Para Ruskin, somente uma sociedade saudável moralmente poderia produzir boa arte $^{13}$. Assim, 0 objeto artístico alcançaria verdadeiro valor estético se fosse produzido, em primeiro lugar, por um homem bom - religioso, ético e moral ${ }^{14} \mathrm{e}$, em segundo lugar, se fosse feito por um homem feliz que, ao manter a comunhão entre trabalho e pensamento, deixaria inscrito na matéria por ele produzida, o prazer ${ }^{15}$ que sentiu em fabricá-la. As práticas artísticas, no pensamento ruskiniano, representariam tanto o testemunho do temperamento moral de uma sociedade quanto deveriam ser um meio de sua educação, uma vez que o objeto artístico deveria ser, também, um objeto ético-moral. Nesta conjuntura, a arquitetura, especialmente o ornamento vivo, assumia um

\footnotetext{
12 Esta compreensão é observada por Cook. In: Ruskin (1904; 1905, introdução); Clark (1950; 1967); Townsend (1951); Frampton (2015) e Lira (2006).

13 Segundo Townsend, a maior preocupação de Ruskin, desde as primeiras obras, seria a melhoria da humanidade. Mas quando o autor se voltou para os assuntos de economia política da arte houve um "momento de virada na carreira de Ruskin". Se no primeiro volume de Pintores Modernos a arte era a salvação da humanidade, no terceiro volume de As Pedras de Veneza, a arte somente poderia ser produzida por uma sociedade saudável econômica, política e moralmente. Cf. Townsend (1951, p. 69). Para Clark (1950; 1967), Landow (1971) e Cook. In: Ruskin (1905, introdução), quando Ruskin se dedica aos textos sobre a economia política da arte, teria havido um amadurecimento no pensamento do autor em relação às questões sociais vivenciadas no século XIX.

14 Cabe evidenciar que arte, moral e religião são indissociáveis no pensamento ruskiniano e alimentam todo o seu discurso. Segundo Clark (1967), o discurso "moralista" e "pregador" de Ruskin teria sido um dos motivos do autor ter se tornado pouco lido no século XX. Durante a segunda metade do século XIX, Ruskin foi uma das figuras mais importantes da literatura inglesa e, na metade do século seguinte, pouco havia sobrado desta reputação. Se no século XIX as pessoas se animavam por um discurso pregador, no século XX, o tom moralizador havia se tornado desinteressante. Cf. Clark (1967, p. xii-xiv).

15 Para Ruskin, o artista ou o artífice não poderiam trabalhar sem prazer; e, também, não poderiam trabalhar somente por causa do prazer. Da mesma maneira, o objeto artístico deveria revelar um equilíbrio entre prazer e propósito moral.
} 
papel de fundamental importância na educação estética ruskiniana. Além de ser uma arte pública e partilhada, que depende da colaboração de homens comuns para a sua edificação, ela representaria o encontro entre homens, entre aqueles que a fizeram e inscreveram a presença viva do seu trabalho na materialidade criada e aqueles que usufruem do edifício construído. Para Ruskin, as virtudes presentes no artista e no artífice que entregaram o seu trabalho na edificação da obra estariam presentes, também, na coisa por eles produzida. E a materialidade feita por homens bons e felizes, teria o poder de ascender as mesmas virtudes naqueles que fossem vivenciar a obra edificada. Mas aqueles que contemplassem tal materialidade também deveriam entregar-se por inteiro. Esta seria a única condição de nos encontrarmos e de nos conhecermos verdadeiramente.

\section{Referências}

AMARAL, Claudio. John Ruskin e a Natureza do Gótico. Arquitextos, n 235, ano 20, 2019.

CLARK, Kenneth. The Gothic Revival: an Essay in the History of Taste. London: Constable, 1950.

CLARK, Kenneth. Ruskin Today. Baltimore: Penguin Books, 1967.

FRAMPTON, Kenneth. História crítica da arquitetura moderna. Tradução de Jefferson Luiz Camargo e Marcelo Brandão Cipolla. São Paulo: Martins Fontes, 2015.

LANDOW, George. Aesthetic and Critical Theory of John Ruskin. Princeton: Princeton University Press, 1971.

LIRA, José Tavares Correia. Ruskin e o trabalho da arquitetura. Risco: Revista de Pesquisa em Arquitetura e Urbanismo, Universidade de São Paulo, São Paulo, v. 4, n. 2, p. 77- 86, 2006.

RUSKIN, John. A economia política da arte. Tradução: Rafael Cardoso. Rio de Janeiro: Record, 2004.

RUSKIN, John. As pedras de Veneza. Tradução: Luís Eduardo de Lima Brandão. São Paulo: Martins Fontes, 1992.

RUSKIN, John. The Seven Lamps of Architecture. London: Library Edition, works, v. viii, 1903. Disponível em: https://bit.ly/2nVdW45.

RUSKIN, John. The Stones of Venice. London: Library Edition, v. I, works, v. ix, 1903 Disponível em: https://bit.ly/2nVdW45. 
RUSKIN, John. The Stones of Venice. London: Library Edition, v. II, works, v. x, 1904 Disponível em: https://bit.ly/2nVdW45.

RUSKIN, John. The Stones of Venice. London: Library Edition, v. III, works, v. xi, 1904 Disponível em: https://bit.ly/2nVdW45.

RUSKIN, John. Two Lectures on the Political Economy of Art (1857-1880). In: RUSKIN, John. A Joy for ever. London: Library Edition, part I, works, v. xvi, 1905, p. 15-174. Disponível em: https://bit.ly/2nVdW45.

RUSKIN, John. Lectures on Architecture and Painting. Adenda aos capítulos I e II. London: Library Edition, part l, works, v. xii, 1904, p. 81-101. Disponível em: https:// bit.ly/2nVdW45.

RUSKIN, John. Modern Manufacture and Design (1859). In: RUSKIN, John. The Two Paths. London: Library Edition, lecture III, works, v. xvi, 1905, p. 319-345. Disponível em: https://bit.ly/2nVdW45.

RUSKIN, John. Influence of Imagination in Architecture (1857). In: RUSKIN, John. The Two Paths. London: Library Edition, lecture IV, works, v. xvi, 1905, p. 346 -374. Disponível em: https://bit.ly/2nVdW45.

RUSKIN, John. Unto this Last (1860). London: Library Edition, part I, works, v. xvii, 1905, p. 5-118. Disponível em: https://bit.ly/2nVdW45.

TOWNSEND, Francis G. Ruskin and the Landscape Feeling: a critical analysis of his thought during the crucial years of his life, 1843-56. Urbana: University of Illinois, 1951. 